\title{
Urine volume reduction during long-duration cave exploration by a light-weight and portable forward osmosis system
}

\author{
Sebastian Engelhardt (DD ${ }^{1 *}$, Katey E. Bender (D) ${ }^{1}$, Jörg Vogel ${ }^{2}$, Stephen E. Duirk ${ }^{3}$, \\ Francisco B. Moore ${ }^{1}$, and Hazel A. Barton (iD) ${ }^{1}$ \\ ${ }^{1}$ Department of Biology, University of Akron, 302 Buchtel Common, Akron, OH 44325, USA \\ ${ }^{2}$ Aquaporin A/S, Nymøllevej 78, 2800 Kongens Lyngby, Denmark \\ ${ }^{3}$ Department of Civil Engineering, University of Akron, Shrank Hall North, 208 Carroll St, Akron, OH 44325, USA
}

\begin{abstract}
The preservation of caves is a challenge during long-duration cave expeditions where human waste can add significant nitrogen to the cave ecosystem. Since the removal of urine that accumulates during a multi-day caving trip is not always feasible due to weight and volume constraints, a light-weight and portable filtration system that is capable of reducing urine volume would be desirable. In this study we tested the Aquaporin Inside hollow fiber membrane in a forward osmosis (FO) setup to evaluate its capability to reduce urine volume while rejecting nitrogenous compounds using different draw solution chemistries and water recovery rates. As a result, we introduce a light-weight and portable FO prototype that was able to reduce urine volume by over $80 \%$. Although total nitrogen (TN) rejection in this process did not exceed $70 \%$, allowing some nitrogen to move across the membrane into the draw solution, evaporation allowed draw solution recycling without loss of nitrogenous compounds into the atmosphere. These data suggest that FO may be a suitable strategy to reduce urine volume and improve methods for nitrogenous waste handling during long-term cave exploration.
\end{abstract}

Keywords: cave exploration, urine filtration, nitrogen mitigation, forward osmosis, aquaporin-based membrane Received 18 June 2020; Revised 25 October 2020; Accepted 25 October 2020

Citation: $\quad$ Engelhardt S., Bender K.E., Vogel J., Duirk S.E., Moore F.B. and Barton H.A., 2020. Urine volume reduction during long-duration cave exploration by a light-weight and portable forward osmosis system. International Journal of Speleology, 49 (3), 229-234. Tampa, FL (USA) ISSN 0392-6672 https://doi.org/10.5038/1827-806X.49.3.2336

\section{INTRODUCTION}

Caves are generally nutrient-limited ecosystems that are sensitive to human impact, including human waste (Borer et al., 2014). This is particularly problematic in hydrologically inactive caves, such as Lechuguilla Cave, New Mexico, which does not receive surface water that would normally flush out contaminants and minimize ecological damage (Cunningham et al., 1995; Davis, 2000; Northup et al., 2003; Johnston et al., 2012; Borer et al., 2014). Human urine is particularly problematic in caves, as it adds significant amounts of nitrogen to what is otherwise a low energy, nitrogen-limited ecosystem (Johnston et al., 2012; Borer et al., 2014).

Due to the size of the cave, expeditions in Lechuguilla Cave can last up to 8 days (Reames, 1999; National Park Service, 2006). Considering that a well-hydrated human excretes about 800 to $2500 \mathrm{~mL}$ of urine per day (Fischbach \& Dunning, 2008), the removal of urine during a week-long cave expedition is not feasible due to the weight (approaching $15 \mathrm{~kg}$ ) and volume that would have to be carried (Johnston et al., 2012; Borer et al., 2014). As a result, urine is poured into the sediment at different designated sites near each camp throughout Lechuguilla Cave (Northup et al., 1997; Reames, 1999; Johnston et al., 2012). If a light-weight, portable and energy-efficient/neutral filtration system could be developed that would reduce urine volume to a practical weight to be carried from the cave, the impacts of such cave exploration could be mitigated.

A promising technology for water removal from urine is forward osmosis (FO), which uses an osmotic differential between a feed solution and a more concentrated draw solution to facilitate water transport across a semi-permeable membrane. This membrane ideally rejects any molecule larger than water, leading to the concentration of the feed stream while the draw stream is being diluted as water crosses the membrane from feed to draw (Cath et al., 2006).

In a recent study, the X-Pack FO system from HTI (Hydration Innovation Technology, Albany, OR) was tested for urine mitigation during cave 
exploration (Borer et al., 2014). The system was not recommended due to a performance loss of water recovery dropping from 80 to $47 \%$ after 1 week of use. Furthermore, the X-Pack required a diffusion time up to 48 hours to process $1.5 \mathrm{~L}$ of urine. A promising alternative membrane that could be integrated into a light-weight and portable FO system is the Aquaporin Inside membrane. This aquaporin-based FO membrane (ABM) makes use of water-selective aquaporin $(\mathrm{AQP})$ proteins that are embedded into its active layer in order to improve solute rejection and water permeability (Tang et al., 2013; Aquaporin A/S, 2018). The Aquaporin Inside membrane is also the only FO membrane on the market that is available in a compact hollow fiber configuration, making it ideal for integrating into a FO system for urine filtration.

The main challenge of a FO system used to recover water from urine is the effective rejection of nitrogenous compounds, including urea, which is difficult due to the uncharged nature and small size of the urea molecule (molecular length of an urea molecule $=0.58 \mathrm{~nm}$, molecular length of a water molecule $=0.28 \mathrm{~nm})($ Engelhardt et al., 2019). In this study, we evaluated the total nitrogen (TN) rejection capabilities of an Aquaporin Inside hollow fiber membrane to reduce the volume of human urine under different draw solution and water recovery scenarios. Our data demonstrate a proof-of-concept prototype of a portable FO system that could continue to be developed for cave exploration.

\section{EXPERIMENTAL}

\section{Forward osmosis membranes}

Two different size hollow fiber FO membrane modules were obtained from Aquaporin A/S (Kongens Lyngby, Denmark). Membrane specifications can be found in Table 1 . We used the larger $2.3 \mathrm{~m}^{2}$ module to determine $\mathrm{TN}$ rejection rates under different draw solutions and water recovery rates while the smaller $0.6 \mathrm{~m}^{2}$ unit was used for the prototyping portion of this study. Prior to first use, both membrane modules were flushed with DI water for 1 hour. After initial wetting, both units were filled with DI water and stored at $2{ }^{\circ} \mathrm{C}$ when not in use.

Table 1. Specifications for the Aquaporin Inside HFFO2 and HHFO.6 membrane module (Aquaporin A/S, 2019a, b).

\begin{tabular}{|l|c|c|}
\hline \multicolumn{1}{|c|}{ Membrane module } & Aquaporin Inside - AQP HFFO2 & Aquaporin Inside - AQP HFFO.6 \\
\hline \multicolumn{1}{|c|}{ Module dimensions } & Length: $\mathbf{3 0 0} \mathbf{~ m m}$, diameter: $\mathbf{7 0} \mathbf{~ m m}$ & Length: $\mathbf{1 5 0} \mathbf{~ m m , ~ d i a m e t e r : ~ 5 0 ~} \mathbf{~ m m}$ \\
\hline & $650 \mathrm{~g}$ & $220 \mathrm{~g}$ \\
\hline Module weight (when filled with DI water)* & $200 \mathrm{~g}$ & $100 \mathrm{~g}$ \\
\hline Module dry weight* & $2.3 \mathrm{~m} 2$ & $0.6 \mathrm{~m} 2$ \\
\hline Active area (lumen side/shell side) & $0.2 \mathrm{~mm}$ & $0.2 \mathrm{~mm}$ \\
\hline Inner diameter of fibers & $15 \pm 1 \mathrm{~L} / \mathrm{m} 2 / \mathrm{hr}$ & $20 \pm 1 \mathrm{~L} / \mathrm{m} 2 / \mathrm{hr}$ \\
\hline Water flux & $0.15 \pm 0.05 \mathrm{~g} / \mathrm{L}$ & $0.15 \pm 0.05 \mathrm{~g} / \mathrm{L}$ \\
\hline Specific reverse salt flux & $60 \mathrm{~L} / \mathrm{h}$ in feed; $25 \mathrm{~L} / \mathrm{h}$ in draw & $25 \mathrm{~L} / \mathrm{h}$ in feed and draw \\
\hline Recommended flow rates & & \\
\hline
\end{tabular}

*determined by the authors

\section{Draw and feed solution composition}

Urine was collected from men (ages 20 - 35) due to chemical stability of male urine (Fong \& Kretsch, 1993) and sterilized through a $0.2 \mu \mathrm{m}$ bottle top vacuum filtration system, which does not change the chemistry of the urine (VWR, Radnor, PA). This sterilized urine was stored at $2{ }^{\circ} \mathrm{C}$ and used within 2 days for all FO experiments. Draw solutions were prepared using D-glucose, $\mathrm{NaCl}$ or $\mathrm{MgCl}_{2}$. All chemicals were obtained from Fisher Scientific (Hampton, NH). TN concentrations from the pre-filtered urine ranged from 6,100 to $7,900 \mathrm{mg} / \mathrm{L}$.

\section{Forward osmosis setup and testing of the AQP-HFFO2 module}

Figure 1 shows a schematic illustration of the FO setup used to determine TN rejection rates under different water recovery rates and draw solutions using the $2.3 \mathrm{~m}^{2} \mathrm{HFFO} 2$ membrane module. Initial volumes of $2 \mathrm{~L}$ were used for the feed as well as for the draw solutions in each experiment. Feed and draw solution were passed through the membrane using peristaltic pumps. As recommended by the membrane manufacturer, we set the feed flow rate to $1,000 \mathrm{~mL} /$ min while the draw stream flow rate was adjusted to $400 \mathrm{~mL} / \mathrm{min}$. The feed stream was passed through the active lumen side of the membrane's hollow fibers, while the draw stream was run through the shell side of the membrane module. The feed solution reservoir was placed on a scale to quantify water recovery (or feed volume reduction) over the course of the FO experiment.

Samples from the feed were taken before each FO experiment while draw samples were collected after

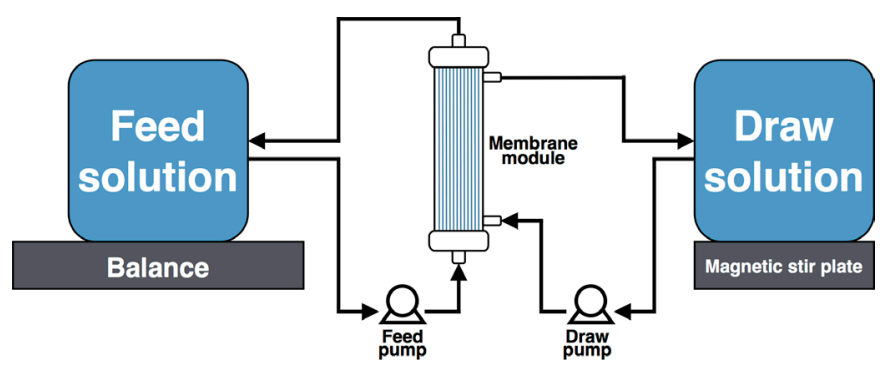

Fig. 1. Schematic overview of the FO system used (Engelhardt et al., 2020). 
a feed volume reduction (or water recovery) of $25 \%$, $50 \%$, and $75 \%$ was achieved. After each experiment, the FO system was flushed with DI water for about 30 minutes. All experiments were performed in triplicate and samples were analyzed immediately after FO. In order to determine TN concentrations, we used the TNTplus 826 assay from Hach (Loveland, CO) following the manufacturer recommended protocol. A 30 minute persulfate digestion at $120^{\circ} \mathrm{C}$ was performed in a Hach DRB 200 heating reactor before TN concentrations were determined using a Hach DR 2800 spectrophotometer.

\section{Rejection rate calculation}

Mass balance-based TN rejection rates $\left(R_{T N}\right)$ were calculated using formula (1) where $V_{d e}$ is the end volume of the draw solution in L, $C_{d e}$ the TN concentration measured in the final draw sample in $\mathrm{mg} / \mathrm{L}, V_{d i}$ the initial volume of the draw solution, $C_{d i}$ the initial TN concentration of the draw stream, $V_{f i}$ the initial volume of the urine feed solution and $C_{f i}$ the urine's initial TN concentration before the FO experiment.

$$
\mathrm{R}_{\mathrm{TN}}=\left(1-\frac{\mathrm{V}_{\mathrm{de}} \cdot \mathrm{C}_{\mathrm{de}} \cdot \mathrm{V}_{\mathrm{di}} \cdot \mathrm{C}_{\mathrm{di}}}{\mathrm{V}_{\mathrm{fi}} \cdot \mathrm{C}_{\mathrm{fi}}}\right) \cdot 100 \%
$$

\section{FO system prototyping and testing}

Four 2 L hydration bladders (Kuyou Sports Goods, Dongguan, China) were used as fluid reservoirs. Tubing fittings and adapters were used to connect the hydration bladders to the $0.6 \mathrm{~m}^{2}$ AQP-HFFP. 6 module. In each experiment, $1 \mathrm{~L}$ of urine was added to the feed reservoir while $500 \mathrm{~mL}$ of a $4 \mathrm{M} \mathrm{NaCl}$ draw solution was used in the draw reservoir. We decided to use a draw solution volume of $500 \mathrm{~mL}$ with a higher osmolarity draw solution to mitigate the dilution of the draw solution and volume processing using $2 \mathrm{~L}$ bladders.

By lifting both liquid-containing bladders above the membrane module, fluid flow was initiated by gravity after opening $10 \mathrm{~mm}$ Keck ramp tubing clamps (ColeParmer, Vernon Hills, IL). Both solutions flowed through the membrane and into the outlet reservoirs, whereupon the tubing clamps were closed and the outlet hydration bladders were weighed to quantify water transport from feed to draw. By turning the FO system upside down, this process could be repeated several times, until water volumes in feed and draw did not change noticeably $(<50 \mathrm{~mL}$ per single pass through membrane module). All experiments were performed in triplicate and samples were taken from the feed and draw reservoir before and after the FO experiments to measure TN concentration and determine TN rejection. The membrane module was flushed with DI water for a few minutes in between experiments.

To recover the $\mathrm{NaCl}$ draw solution, we used a Jetboil Flash stove (Johnson Outdoors, Racine, WI) to boil water off the draw solution to $500 \mathrm{~mL}$. We repeated this procedure after three consecutive $\mathrm{FO}$ experiments and monitored changes of TN concentration in the draw solution.

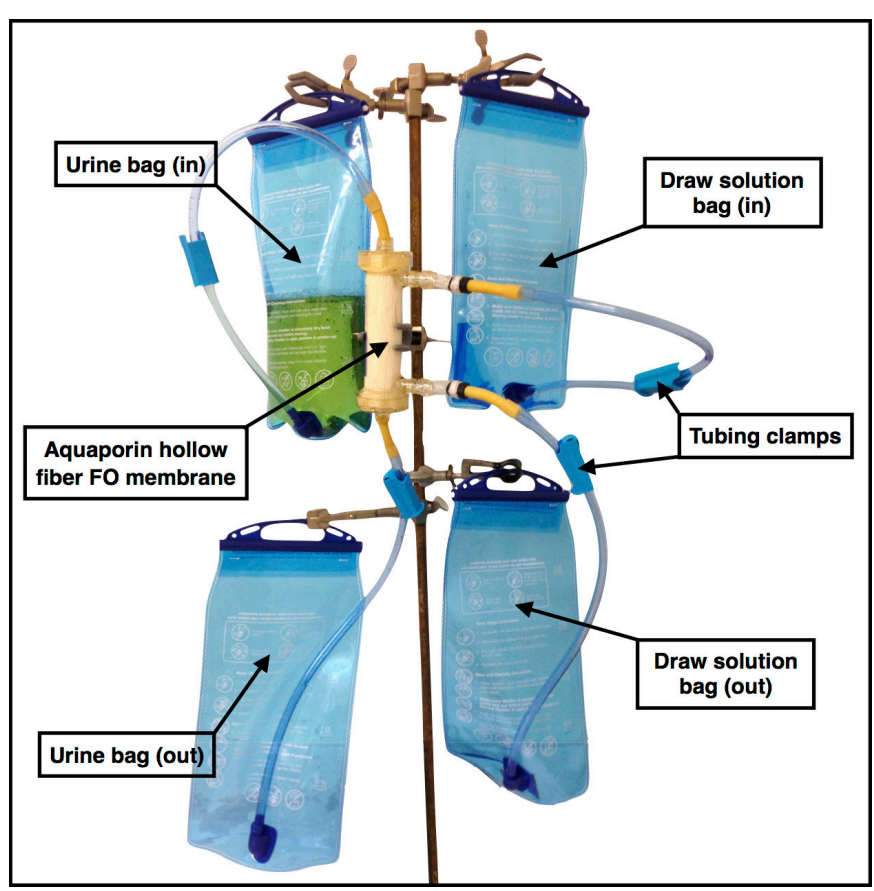

Fig. 2. Schematic illustration of the tested light-weight FO prototype.

\section{RESULTS AND DISCUSSION}

\section{TN rejection for the AQP-HFFO2 module}

We used the larger size $2.3 \mathrm{~m}^{2}$ AQP-HFFO2 module to determine $\mathrm{TN}$ rejection under a range of water recovery rates and draw solutions. This module is the second generation of the $2.3 \mathrm{~m}^{2}$ AQP-HFFO module, which has already been tested for its capability to reject nitrogenous compounds from urea solutions and synthetic urine in previous studies (Engelhardt et al., 2019, 2020). By using a module of the same size, identical flow rates and fluid volumes could be used, allowing for a better comparison of our results to existing data.

Significant urine concentration and volume reduction (see Fig. 3) could be achieved by the FO process as water is absorbed into the draw solution. Figure 3 shows an image of the feed and draw solution before and after FO. The initial draw and feed volumes (Fig. 3a) were $2 \mathrm{~L}$ while the TN concentration in the feed was $5.8 \mathrm{~g} / \mathrm{L}$. After the experiment (Fig. 3b) the feed volume dropped to $0.55 \mathrm{~L}$ with a TN concentration of $16.7 \mathrm{~g} / \mathrm{L}$, while the final draw solution volume was $3.45 \mathrm{~L}$ with a TN concentration of $0.7 \mathrm{~g} / \mathrm{L}$.

We repeated this experiment with the synthetic urine feed solution used in previous studies (Engelhardt et al., 2019, 2020). TN rejection for artificial urine was

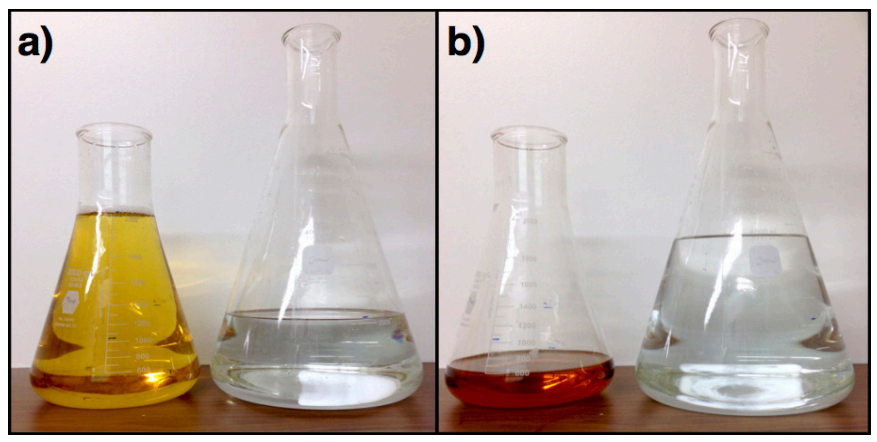

Fig. 3. Urine feed solution and $\mathrm{NaCl}$ draw solution a) before and b) after FO. 
significantly lower if compared to human urine, approximating $54 \%$ after $75 \%$ water recovery using a $2 \mathrm{M} \mathrm{NaCl}$ draw (data not shown); however, the TN rejection rates between the HFFO2 membrane and the first generation $\mathrm{HFFO}$ modules used in previous studies (e.g., $46 \% \mathrm{TN}$ rejection after $75 \%$ water recovery using a $2 \mathrm{M} \mathrm{NaCl}$ draw solution; see Engelhardt et al., 2020), demonstrated higher TN rejection with the newer membrane modules. As these modules continue to improve, a similar improvement in TN selectivity may be seen.

Average TN rejection rates for the AQP-HFFO2 module under different water recovery rates and draw solutions are displayed in Fig. 4.

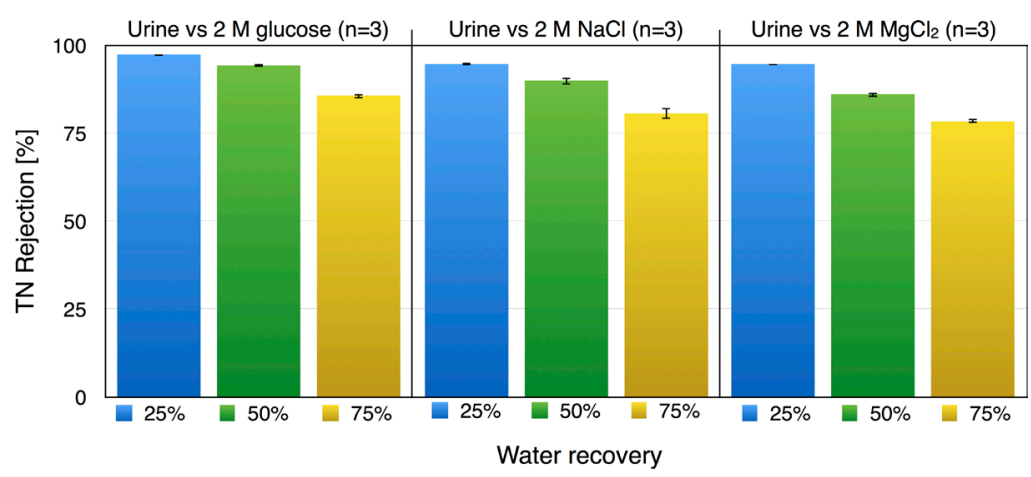

Fig. 4. TN rejection for the AQP-HFFO2 membrane module under different water recovery rates when using urine feed solutions against $2 \mathrm{M}$ glucose, $2 \mathrm{M} \mathrm{NaCl}$ and $2 \mathrm{M} \mathrm{MgCl}_{2}$ draw solutions. All experiments were done using independent replicates. Confidence intervals represent SE $(n=3)$.

Overall, TN rejection decreased with increasing water recovery. As previous studies have suggested, this is due to the increasing concentration of the feed stream, leading to a higher passage of urea molecules across the membrane, as well as the declining rate of draw solution dilution as a result of decreasing osmotic pressure over time (Engelhardt et al., 2019, 2020). Lowest overall TN rejection was observed when $\mathrm{MgCl}_{2}$ draw solutions were being used (e.g., $78 \%$ TN rejection after $75 \%$ water recovery), while the highest overall rejection was attained for glucose draw solutions, averaging $86 \%$ TN rejection after $75 \%$ water recovery. Statistical analyzes showed significant difference in TN rejection between the different draw solutions for all three water recovery rates tested (ANOVA, $\mathrm{P}<0.05, \mathrm{n}=3$ ). The utilization of glucose might allow for a drinkable draw solution that could be consumed by the caver during cave exploration. Therefore, high water recovery would be crucial, not only to effectively reduce urine volume, but also to dilute the glucose draw solution to make it drinkable. Nonetheless, the loss of $14 \%$ TN into the draw solution is not safe for a drinkable glucose draw solution, as prolonged consumption of a high TN solution may lead to the accumulation of nitrogenous compounds in the caver's blood stream and substantial stress on the kidneys, with additional need for hydration, leading to greater urine output. Therefore, the more inert $\mathrm{NaCl}$ or $\mathrm{MgCl}_{2}$ draw solutions may be preferable, as these could possibly be left inside the cave for reuse. $\mathrm{NaCl}$ has the advantage that its lower molecular weight makes it lighter, reducing the overall weight to be brought into the cave. For example, to create $1 \mathrm{~L}$ of a $2 \mathrm{M}$ (or $0.5 \mathrm{~L}$ of a $4 \mathrm{M}$ ) $\mathrm{NaCl}$ draw solution, $117 \mathrm{~g}$ of $\mathrm{NaCl}$ are required compared to $190 \mathrm{~g}$ of $\mathrm{MgCl}_{2}$. We therefore focused our work on $\mathrm{NaCl}$ as the draw solute in all prototype tests.

\section{FO prototype testing}

The progression of feed and draw solution volume with increasing number of passes $(1$ pass $=$ complete fluid transfer from liquid-containing to empty bladders) through the $0.6 \mathrm{~m}^{2} \mathrm{AQP}-\mathrm{HFFO} .6$ membrane module is shown in Fig. 5 . After 5 passes through the membrane, water transfer from feed to draw became minimal $(<50 \mathrm{~mL})$ as the system approached osmotic equilibrium. The average volume reduction of the feed solution (urine) after 5 passes through the membrane was $80.87 \%(\mathrm{SE}=0.43 \%)$ and the total experimental time to process $1 \mathrm{~L}$ of urine ranged from 15 to 20 minutes. TN rejection averaged $69.82 \%(\mathrm{SE}=1.00 \%)$ and the mean TN concentration of the final draw samples was $2.05 \mathrm{~g} / \mathrm{L}(\mathrm{SE}=0.07 \mathrm{~g} / \mathrm{L})$. The mean TN concentration of the initial urine was $9.09 \mathrm{~g} / \mathrm{L}$ $(\mathrm{SE}=0.3 \mathrm{~g} / \mathrm{L})$.

Even though TN rejection of the membrane did not exceed $70 \%$, the resulting draw solution after the FO process contained much lower TN values (Fig. 3). We therefore decided to test whether the salts in the draw solution could be recovered for re-use by evaporation of the water in the draw solution. To do this, we used an outdoor stove often used during cave expeditions (e.g., https://www.derekbristol.com/stoves). By boiling the draw solution in the stove, we were able to reduce the volume to $500 \mathrm{~mL}$. By repeating this process three times, the TN concentration in the boiled-down draw solution increased from 5.4 to $13.6 \mathrm{~g} / \mathrm{L}$ while TN rejection increased from 68 to $76 \%$, presumably through osmotic effects and changes in chemical gradients from the accumulation of urea in the draw solution. Overall, our data demonstrated that nitrogenous compounds stay in the draw solution, as TN quantified in the draw prior to the evaporation step matched the amount of TN measured in the recovered draw solution after boiling. Furthermore, no noticeable odors were released during the draw solution evaporation process. These experiments therefore confirm that draw solution recovery via

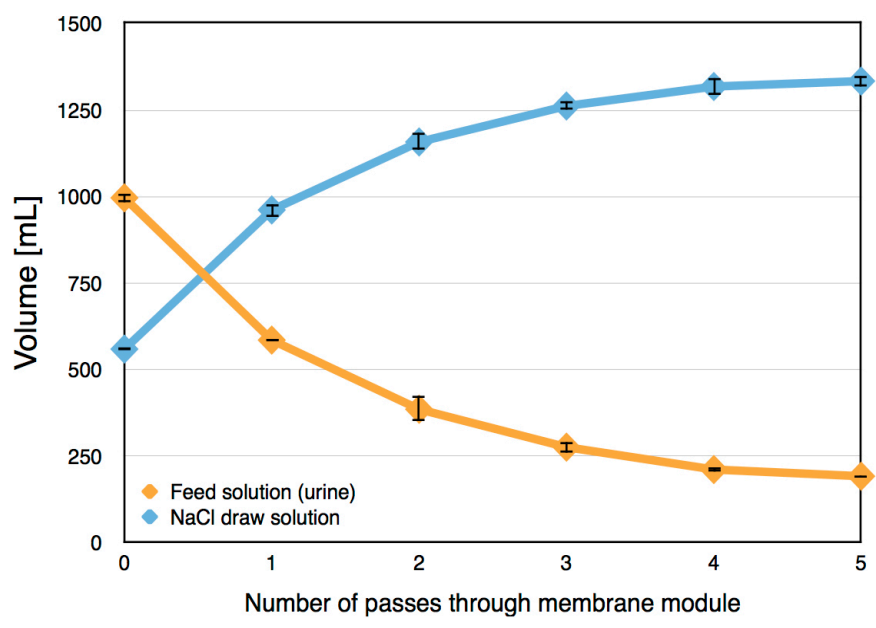

Fig. 5. Volume changes of feed and draw solution with passes through the AQP-HFFO.6 membrane module. All experiments were done using independent replicates. Confidence intervals represent SE $(n=3)$. 
evaporation may be an alternative strategy to avoid the deposition of $\mathrm{NaCl}$ or $\mathrm{MgCl}_{2}$ draw solutions in the cave; however, we did not test whether the evaporate from boiling urine contained TN without FO preprocessing, which would reduce the overall complexity of this approach.

Considering that this FO membrane did not reject the entire TN of the urine, draw solution recovery and re-use may be a possible strategy to prevent adding excessive amounts of weight and volume to the equipment that must be carried. For comparison: if we assume that a single caver excretes about $2 \mathrm{~L}$ of urine per day throughout an 8 day cave expedition, the total fluid volume that would ideally be removed from the cave would amount to $16 \mathrm{~L}$. If we consider that the draw solution can be reused in multiple FO processes while urine volume can be reduced by $80 \%$, only a total of about 3.2 L of additional volume (plus remaining salts and accumulated nitrogenous compounds of the final evaporated draw solution) would have to be removed from the cave instead of $16 \mathrm{~L}$ of unprocessed urine. The recovery of the draw solution would also minimize the amount of water needed for draw solution setup. Nonetheless, the evaporation of water from the draw solution took a considerable amount of energy (in the form of butane gas) and may not provide a practical solution. Additionally, evaporation was carried out under laboratory conditions and not the high humidity of a cave, which may further reduce efficiency. As ABMs become more selective, it may be possible that FO may exclude sufficient TN that the glucose/drinking approach may be safe. Alternatively, more cave appropriate draw salts (such as $\mathrm{CaSO}_{4}$ ) could be used that would limit chemical impact on the cave system.

In setting up the prototype, we used a small FO module $\left(0.6 \mathrm{~m}^{2}\right)$ that would be easier to carry into the cave. Nonetheless, this membrane required five passes of the urine through the membrane column to treat $1 \mathrm{~L}$ of urine and took 20 minutes. Given that an eight person expedition could produce over $100 \mathrm{~L}$ of urine in one week, this obviously is an impractical approach. The larger $2.3 \mathrm{~m}^{2} \mathrm{FO}$ module may be more cost effective ( $\$ 450$ each as opposed to $\$ 400$ for the $0.6 \mathrm{~m}^{2}$ module) and, with an energy efficient circulation system, could provide a more practical approach. It is hoped that future work can determine the weight and power constraints that would allow such a module to be engineered to work in the cave environment.

\section{CONCLUSION}

Our data suggest that FO could be an effective strategy to reduce urine volume during long-duration cave exploration; however, TN rejection by the FO membrane did not exceed $86 \%$ at water recovery (or urine volume reduction) rates of $75 \%$. To allow for drinkable sugar draw solutions that could be consumed during cave expedition, significantly higher TN rejection would be desirable. Alternatively, $\mathrm{NaCl}$ or $\mathrm{MgCl}_{2}$ draw solutions could be disposed of inside the cave, as they represent more inert solutions containing lower nitrogen concentrations compared to the urine, although the impact of these salts on water chemistry within the cave would need to be carefully considered. Our draw solution recovery experiments showed that nitrogenous compounds remained in the draw solution during water evaporation, which suggests that the entire removal of nitrogenous waste from the cave is feasible. We suggest that more work should be done with respect to prototype size and whether a pump should be used to circulate urine and draw solution through the FO system, which would help regulating feed and draw flow rates more precisely. Furthermore, membrane performance has to be evaluated after long-term usage as biofouling may occur if the membrane module is not adequately rinsed and properly stored after FO.

\section{ACKNOWLEDGEMENTS}

This work was supported by a grant from Carlsbad Caverns National Park and the US National Park Service. We thank Rod Horrocks and Erin Lynch for their support throughout this research project and two anonymous reviewers for their comments, which improved the quality of this manuscript. We would also like to acknowledge the members of the Barton lab who volunteered as urine donors during this study and Aquaporin A/S (Kongens Lyngby, Denmark) for their technical assistance.

Authorship statement: $\mathrm{SE}$ and $\mathrm{HAB}$ designed and directed the study. SE performed the measurements and analyzed the data. SE, HAB and KEB wrote the paper with input from all authors and developed the prototype tested in this study. JV provided expert knowledge regarding membrane specifics. SED supported the planning of the experimental campaign. SE, HAB, SED, JV, and FBM revised the manuscript.

\section{REFERENCES}

Aquaporin A/S. Aquaporin InsideTM forward osmosis membrane products. https://aquaporin.dk/products/ fo/ [accessed: July 3, 2018].

Aquaporin A/S, 2019a. Aquaporin-HFFO2-Datasheet-1-7. https://aquaporin.com/wp-content/uploads/2020/ 05/Aquaporin-HFFO2-Datasheet_May-2020.pdf

Aquaporin A/S, 2019b. Aquaporin-HFFO.6-datasheet. https://aquaporin.com/wp-content/ uploads/2020/05/Aquaporin-HFFO.6-Datasheet May-2020.pdf

Borer, C., Stiles, W., Stevenson, J., Cabanillas, K., 2014. Assessment of forward osmosis as a possible mitigation strategy for urine management during extended cave exploration. Journal of Cave and Karst Studies, 76, 26-29. https://doi.org/10.4311/2012LSC0269

Cath, T., Childress, A., Elimelech, M., 2006. Forward osmosis: Principles, applications, and recent developments. Journal of Membrane Science, 281, 7087. https://doi.org/10.1016/j.memsci.2006.05.048

Cunningham, K.I., Northup, D.E., Pollastro, R.M., Wright, W.G., LaRock, E.J., 1995. Bacteria, fungi and biokarst in Lechuguilla Cave, Carlsbad Caverns National Park, New Mexico. Environmental Geology, 25, 2-8. https://doi.org/10.1007/BF01061824 
Davis, D., 2000. Extraordinary features of Lechuguilla Cave, Guadalupe Mountains, New Mexico. Journal of Cave and Karst Studies, 62, 147-157.

Engelhardt, S., Vogel, J., Duirk, S.E., Moore, F.B., Barton, H.A., 2019. Urea and ammonium rejection by an aquaporin-based hollow fiber membrane. Journal of Water Process Engineering, 32, 100903. https://doi.org/10.1016/j.jwpe.2019.100903

Engelhardt, S., Vogel, J., Duirk, S.E., Moore, F.B., Barton, H.A., 2020. Assessment of urea hydrolysis as a pretreatment strategy to improve total nitrogen rejection from urine using aquaporin-based membranes in forward osmosis. Journal of Water Process Engineering, 34, 101135. https://doi.org/10.1016/j.jwpe.2020.101135

Fischbach, F.T., Dunning, M.B., 2008. A manual of laboratory and diagnostic tests ( $8^{\text {th }}$ Ed.). Williams \& Wilkins, Philadelphia, 1317 p.

Fong, A.K., Kretsch, M.J., 1993. Changes in dietary intake, urinary nitrogen, and urinary volume across the menstrual cycle. The American Journal of Clinical Nutrition 57, 43-46. https://doi.org/10.1093/ajcn/57.1.43

Johnston, M., Muench, B., Banks, E., Barton, H., 2012. Human urine in Lechuguilla Cave: the microbiological impact and potential for bioremediation. Journal of Cave and Karst Studies, 74, 278-291. https://doi.org/10.4311/2011MB0227

National Park Service, 2006. Cave and karst management plan. Carlbad Caverns National Park, US National Park Service.

Northup, D.E., Beck, K.M., Mallory, L.M., 1997. Human impact on the microbial communities of Lechuguilla Cave: Is protection possible during active exploration? [abstract]. Journal of Cave and Karst Studies, 59, 166.

Northup, D.E., Barns, S.M., Yu, L.E., Spilde, M.N., Schelble, R.T., Dano, K.E., Crossey, L.J., Connolly, C.A., Boston, P.J., Natvig, D.O., Dahm, C.N., 2003. Diverse microbial communities inhabiting ferromanganese deposits in Lechuguilla and Spider Caves. Environmental Microbiology, 5, 1071-1086. https://doi.org/10.1046/j.1462-2920.2003.00500.x

Reames, S. (Ed.), 1999. Deep secrets: the discovery \& exploration of Lechuguilla Cave. Cave Books, St. Louis, MO.

Tang, C.Y., Zhao, Y., Wang, R., Hélix-Nielsen, C., Fane, A.G., 2013. Desalination by biomimetic aquaporin membranes: Review of status and prospects. Desalination, 308, 34-40. https://doi.org/10.1016/j.desal.2012.07.007 